\title{
La compra silenciosa. Arrendamientos, estabilidad y mejoras en la agricultura valenciana de regadío (1850-1930)
}

\section{The silent purchase. Cash tenancy, tenant stability and improvements in Eastern Spanish farming (1850-1930)}

\author{
SAMUEL GARRIDO HERRERO \\ Universidad Jaume I de Castellón \\ SALVADOR CALATAYUD GINER \\ Universidad de Valencia
}

RESUMEN

Este artículo analiza cómo fue posible, en el regadío valenciano, un desarrollo agrario basado en el arrendamiento de pequeñas explotaciones. Del estudio de los contratos firmados en la huerta de Gandía se deduce, en primer lugar, que los arrendatarios ocupaban la parcela durante un período bastante prolongado de tiempo, que tendió a crecer durante la segunda mitad del siglo XIX; $\mathrm{y}$, en segundo, que a menudo los cultivadores eran indemnizados al finalizar su contrato por las mejoras que habían introducido. A largo plazo, todo ello consolidó su posición, porque el cultivador se convirtió en "semipropietario" de hecho de la tierra mejorada.

Por su parte, los terratenientes rentistas obtuvieron a corto y medio plazo una renta alta y segura, pero perdieron en parte su capacidad para gestionar los arriendos, como perdieron también en el largo plazo, a favor de sus antiguos arrendatarios, la propiedad legal de algunas de sus tierras.

PALABRAS CLAVE: Arrendamientos, Mejoras, Contratos agrarios, Propiedad de la tierra, España contemporánea

\section{ABSTRACT}

In the 19th century, Eastern Spanish "huertas" witnessed a dramatic growth and intensification of their output, which was achieved by means of an agrarian development model based on a peasant economy and the cash renting of small plots. This paper looks at characteristics and longrun implications of that model. On the one hand, tenants were able throughout the second half of the century to remain on their farms for an increasingly longer period, and often they were eventually reimbursed by the improvements they had introduced. Because of that, agrarian production increased and improved, what allowed landlords to obtain a higher rent. But, on the other, landlords lost capacity to control and manage the tenant holdings. As a result, tenant farmers consolidated their position, becoming first "semi-owners" of the land they cultivated and, very often, legal proprietors afterwards.

KEY WORDS: Cash tenancy, Improvements, Agrarian contracts, Land ownership,

Contemporary Spain

JEL Codes: N53, Q15, R14 


\section{Introducción ${ }^{1}$}

$\mathrm{L}$

a amplia presencia del cultivo de regadío ha hecho del litoral valenciano una de las áreas con mayor productividad del suelo de la Península Ibérica. Este modelo agrario tenía una larga tradición histórica, pero durante la segunda mitad del siglo XIX experimentó una ampliación importante y transformaciones profundas en algunos de sus rasgos básicos. La ampliación implicó el crecimiento de las superficies regadas y un aumento de la producción en cultivos que, en muchos casos, sólo se habían practicado hasta entonces a pequeña escala. Las transformaciones consistieron, fundamentalmente, en el relevo progresivo de productos destinados a la industria, como la seda y el cáñamo, por plantas alimentarias que otorgaban nuevas oportunidades de comercialización de las cosechas, dentro y fuera de España. Al mismo tiempo, el trigo experimentaba cierto retroceso aun manteniendo una presencia destacada en el regadío, donde ofrecía rendimientos comparables a los de la Europa noratlántica. Sin embargo, hasta que el naranjo se convirtió en una opción mayoritaria, avanzado ya el siglo XX, no existió un producto que fuera capaz de ocupar por sí solo las amplias áreas de regadío. Por el contrario, lo que encontramos al entrar en el Novecientos es un conjunto de especializaciones de carácter local o comarcal: arroz, hortalizas, rotaciones en torno al trigo y al maíz, naranjo, etc. Por su parte, donde no alcanzaba el riego artificial, la viticultura había creado oportunidades importantes de desarrollo agrario. Ambos espacios, regadío y secano, convivían incluso a escala de cada localidad, de modo que casi todos los propietarios poseían tierras de los dos tipos.

La dinámica de esta estructura de la producción agraria implicaba recurrentes procesos de cambio, en los que la convivencia de los viejos cultivos en decadencia con los nuevos en ascenso era un fenómeno habitual. Nada más alejado, pues, de un cuadro de cultivos fijado secularmente. En estas condiciones, no puede extrañar que el rasgo básico de este modelo fuera la capacidad de los agricultores para afrontar tales cambios y adaptarse sucesivamente a las nuevas oportunidades de los merca$\operatorname{dos}^{2}$. Al mismo tiempo, aunque había exigencias comunes a toda la agricultura intensiva, la multiplicidad de especializaciones creaba condiciones específicas en cada zona por lo que respecta a las formas de organizar la producción.

[Fecha de recepción del original, julio de 2006. Versión definitiva, octubre de 2006]

1 Este trabajo ha contado con la ayuda de los Proyectos de Investigación BHA2002-01006 del Ministerio de Ciencia y Tecnología y SEJ2004-00799/ECON de la DGICYT. El texto se ha beneficiado de los comentarios y las críticas de Jesús Millán, así como de los efectuados por los evaluadores anónimos de Investigaciones de Historia Económica. Sus autores también quieren agradecer las facilidades prestadas por Jesús Alonso y todo el personal del Archivo Municipal de Gandía.

2 Garrabou (1985). 
La explotación indirecta estaba muy generalizada y, por lo que respecta al regadío del área litoral, se basaba casi exclusivamente en el arrendamiento. Hacia 1860, dependiendo de la comarca, entre el 40 y el 80 por 100 de la superficie cultivada estaba sujeta a contratos de arrendamiento. Los grandes propietarios lo usaban mayoritariamente, aunque el cultivo directo no era raro y las estrategias de los terratenientes incluían el paso de una modalidad a otra en función de modificaciones en las circunstancias que influían sobre este modelo agrario. Las unidades de explotación cedidas en arriendo solían ser de tamaño reducido, de modo que en la base del cultivo se encontraba un elevado número de pequeños colonos obligados a contratar con los arrendadores para huir de la precariedad o de la carencia de tierras propias.

En suma, una de las agriculturas más avanzadas de la Península Ibérica se encontraba, en buena parte, en manos de arrendatarios modestos. La pregunta clave sigue siendo cómo y en qué medida estas formas de cultivo indirecto contribuyeron a impulsar o a frenar el desarrollo agrario. En el presente trabajo pretendemos acercarnos a esta cuestión a través de dos componentes centrales en la relación de arrendamiento: la estabilidad de los cultivadores en la explotación y los estímulos a la introducción de mejoras en el cultivo.

Las prácticamente inabarcables discusiones sobre la eficiencia económica de las diversas modalidades de explotación indirecta han apuntado hacia la duración efectiva de los contratos como una de las cuestiones fundamentales a considerar. La idea bien conocida es que la continuidad de un mismo cultivador en una explotación durante un largo período favorece la inversión, la introducción de nuevos cultivos y el desarrollo agrario, mientras que una permanencia corta tendría los efectos contrarios. En lo que a Valencia se refiere, en las décadas finales del siglo XIX comenzó a arraigar entre los contemporáneos la opinión de que en una parte muy significativa de las huertas y marjales predominaba un "arrendamiento consuetudinario" caracterizado por una absoluta estabilidad, hasta el punto de que a menudo era susceptible de ser traspasado por herencia de padres a hijos. La idea subyacente era la misma que articulaba la trama de La Barraca (1889), la famosa novela de Vicente Blasco Ibáñez: si el colono no incurría en "grave incumplimiento", el dueño no osaba prescindir de él sin una generosa compensación monetaria para que la marcha fuera voluntaria. En caso contrario, le sería muy difícil encontrar otro labrador que se hiciera cargo de la tierra, bien por solidaridad con el desahuciado, bien porque sabía que sufriría el desprecio de los vecinos y las represalias de familiares y amigos del anterior colono, "que frecuentemente han ensangrentado las huertas valencianas"3. A partir de esa premisa, se solía llegar a dos conclusiones de aparente difícil encaje. 
Por un lado, se podía decir, como el Registrador de la Propiedad de Valencia en 1888, que el dueño se veía privado "de la libre facultad de disponer de sus bienes, haciendo imposible el aumento del precio del arrendamiento y el cambio de arrendatario"4. "No se respeta el derecho de propiedad", en palabras de Orellana ${ }^{5}$. Pero, simultáneamente, ese hecho se podía considerar, cuando convenía — por ejemplo, cuando alguien pretendía demostrar que en Valencia era superflua una reforma agraria-, como una prueba de que en el regadío seguramente más rico de España reinaba la armonía entre las clases y estaba ausente la conflictividad 6 .

En parte como reacción a esto último, cuando la historia agraria valenciana comenzó a adquirir madurez, ya bien traspasado el ecuador del siglo XX, se perfilaron dos líneas interpretativas. Algunos historiadores identificaron el (para ellos mal llamado) "arrendamiento consuetudinario" con la enfiteusis y con una "pervivencia feudal"7. Pero el estudio de los arrendamientos escriturados - que, entre otras cosas, mostraban que el propietario podía participar a través de diversos mecanismos en la dirección de la explotación - hizo concluir a otros investigadores que se trataba de una relación contractual a corto plazo ${ }^{8}$ : según la mayor muestra analizada hasta el momento, el 85 por 100 de los contratos escriturados en el País Valenciano durante el siglo XIX se concertaron por seis o menos años ${ }^{9}$. Incluso así, numerosos indicios sugerían que la duración efectiva del contrato podía ser, gracias a la "tácita reconducción", mayor que la escriturada y, en ocasiones, los hijos sucedían a sus padres como arrendatarios de una misma parcela ${ }^{10}$.

De hecho, en las condiciones específicas del modelo productivo mediterráneo que se practicaba en Valencia, la duración del arrendamiento debía tener repercusiones transcendentales ${ }^{11}$. La cuestión clave en ese sentido era el potencial de mejora y de aumento de los rendimientos que tal agricultura ofrecía, que derivaba tanto de la existencia del regadío como de la multiplicidad de opciones productivas. Éstas

$4 \quad$ Citado por Romero (1983), p. 260.

5 Orellana (1886), p. 14. Ideas similares, en Bernabé (1907), p. 4; Monforte (1922), p. 9, y Garrido-Juan (1943), p. 44.

6 Según Burriel y Oller (1929), p. 118, “Merced a nuestro especial sistema de arrendamiento, puede decirse [...] que en Valencia no hay cuestión social agraria". En la misma línea, Garrido-Juan (1943), p. 60.

Sebastià y Piqueras (1987), pp. 237-274.

Goerlich (1982); Gimeno (1983); Pons (1990), y Castellanos y Fernández-Pacheco (1991).

Pons (1990), p. 183.

10 Goerlich (1982), pp. 199 y 214; Romero (1983), p. 256; Pons (1990), p. 193; Ruiz (1991), pp. 95-96; y Ardit (1991).

11 Cuestión ya apuntada por los contemporáneos. Bernabé (1907), p. 4, se quejaba de que los dueños vieran limitado su derecho de propiedad, pero "a esta seguridad [de los colonos] en el disfrute de las fincas débese el próspero estado de la Huerta, así como las mejoras que se han ido allí acumulando una tras otra generación". 
incluían, en un lugar destacado, el cultivo de árboles, tanto de secano como de regadío, que requerían de un tiempo de espera elevado antes de que la inversión comenzara a dar sus frutos. Se tratara de árboles o de cultivos anuales, los rendimientos en el regadío son en general muy sensibles al empleo de trabajo, de fertilizantes y a los cuidados en el mantenimiento de las infraestructuras de riego. Por tanto, hay un amplio margen para que los cultivadores introduzcan cambios técnicos, a menudo pequeñas mejoras en las que el factor trabajo tiene un peso decisivo, pero que también incluyen la compra de bienes de producción.

Pensemos, por ejemplo, que la fertilización artificial es una práctica cuyos efectos pueden prolongarse en el tiempo en cultivos de ciclo corto: si un arrendatario teme ver interrumpida su permanencia, es probable que no tenga incentivos para fertilizar la tierra de manera adecuada en la etapa final del contrato. Otro ejemplo sirve para ilustrar una cuestión de suma importancia en las huertas: los trabajos de mantenimiento de las infraestructuras de riego no consisten sólo en prestar atenciones a las acequias, regueros o compuertas, ya que los riegos producen un arrastre de tierra desde la parte alta a la baja de la parcela, que hay que corregir regularmente para evitar que la finca se desnivele y el agua deje de fluir de manera adecuada. Los beneficios derivados de esas pequeñas intervenciones con efectos acumulativos aún se hacían más evidentes donde los suelos eran muy arcillosos. Para contrarrestar los inconvenientes de este tipo de suelos ${ }^{12}$, los agricultores trataban de mejorarlos y para ello practicaban abundantes hormigueros y los mezclaban con otra clase de tierras o con arena de mar y río. Pero los elementos finos son arrastrados por el agua en mayor medida que estos aportes; de manera que, en el seno de cada parcela, se produce un desequilibrio en la composición mecánica del suelo, que, de no haber una intervención constante por parte del agricultor, tiende a ser más arcilloso, y por tanto de progresiva peor calidad, a medida que está más lejos de las entradas del agua. Evidentemente, el arrendatario podía llegar a la conclusión de que, a corto plazo, le convenía obtener una cosecha menor a cambio de dedicar menos tiempo a solucionar esos problemas, lo que repercutiría en una pérdida de valor de la finca porque, tarde o temprano, la situación se haría insostenible, y para mantener los rendimientos en un nivel aceptable habría que acometer costosos trabajos de remoción de tierras.

La larga duración del arrendamiento es en todos los lugares una condición favorable a la innovación, pero donde las mejoras potencialmente susceptibles de ser introducidas por los colonos eran muy limitadas, como en los secanos cerealistas de

12 Si contienen árboles, éstos suelen tener un porte reducido debido a la compresión de sus raíces. Su escasa permeabilidad favorece el estancamiento de las aguas y la aparición de enfermedades. Presentan un tempero muy corto (porque la arcilla se adhiere en exceso cuando está demasiado húmeda y es muy dura cuando se seca), lo que significa que hay pocos días aptos para trabajarlos. 
la España interior, el corto plazo y la ausencia de reconducción afectaban mucho a las condiciones de vida de los cultivadores sometidos a los "arriendos por necesidad" de que habla Robledo ${ }^{13}$, pero tenían que ejercer una influencia menor sobre el progreso agrario. La seguridad del arrendatario de permanecer en la tierra durante un período dilatado, en cambio, había de tener una importancia decisiva para el adecuado funcionamiento del sistema en las huertas valencianas.

De todas maneras, aunque los contratos largos podían favorecer la mejora de la agricultura por la vía de aplazar la aparición de comportamientos oportunistas entre los arrendatarios, difícilmente podían ser una condición suficiente para erradicar ese tipo de actuaciones. Según un argumento habitual, un arrendatario al que el propietario ofrezca un contrato largo será propenso a no escatimar esfuerzos para la mejora de la explotación, lo que actúa en beneficio de ambas partes. Cuando se razona de esta manera, implícitamente se está empleando lo que en la teoría de juegos se conoce como la estrategia del "ojo por ojo": la primera vez que una persona se relaciona con otra tiende a cooperar, y la siguiente vez simplemente sigue el mismo comportamiento adoptado antes por la parte contraria ${ }^{14}$. Así, si los dos jugadores se relacionan repetidamente a lo largo del tiempo, el resultado será la cooperación (que en nuestro caso equivale a la introducción de mejoras por parte de un arrendatario que goza de estabilidad) en todas y cada una de las ocasiones. Pero no puede olvidarse que una de las muchas condiciones para que la estrategia del "ojo por ojo" tenga éxito es que los jugadores no sepan cuándo dejarán de interrelacionarse ${ }^{15}$, porque, si no se verificase ese supuesto, cesarían de colaborar cuando ese momento se acercase. Si los contratos se respetan, el arrendatario sabe que, por más largo que sea el que disfruta, en algún momento tendrá que abandonar la explotación y acabará perdiendo la inversión, por lo que pretenderá resarcirse sobreexplotando la tierra durante la etapa final de la relación. Como ya se ha dicho, la solución mayoritariamente adoptada por los propietarios valencianos consistió en no recurrir a contratos largos, sino a contratos cortos que, si el arrendatario cumplía, se iban renovando anualmente de manera tácita. Pero así tampoco se resolvía por completo el problema de las mejoras, porque la reconducción o no del contrato dependía en exclusiva de la voluntad de una de las partes, el propietario, que era el único con posibilidad de saber cuando finalizaría la relación, y era ahora quien tenía más alicientes para actuar de manera no cooperativa, hasta el punto de que las mejoras podían repercutir en contra del arrendatario. Es lo que le sucedió a cierto personaje de La Barraca, que cuando el dueño le planteó escoger entre pagar más renta o marcharse "protestó, y hasta lloró recordando los méritos de su familia, que

Robledo (1984), p. 161.

Axelrod (1984).

Frank (1992), pp. 528-529. 
había perdido la piel en aquellos campos para hacer de ellos los mejores". Pero el dueño se mostró inflexible: “¿Eran los mejores?...Pues a pagar más"16.

La seguridad en la permanencia en la tierra por parte del arrendatario tenía que ser, en definitiva, un factor de importancia primordial en el regadío valenciano, pero, como se insistirá en las páginas que siguen, para que el cultivador se mostrara dispuesto a invertir se requería otra condición: el pago por parte del propietario de las mejoras realizadas en la finca. El objetivo de este trabajo es vincular la duración real del arrendamiento con ese pago (o no pago) de las mejoras. En el apartado segundo se lleva a cabo una cuantificación de la duración real de los arrendamientos en una zona destacada del regadío valenciano, la huerta de Gandía. En el tercer apartado se aborda el alcance que tenía la obligación de pagar mejoras en esa misma área y se relaciona la práctica de tales pagos con la duración de los arriendos. Finalmente, en las conclusiones se destacan las consecuencias del cultivo indirecto estudiado sobre el desarrollo agrario, sobre las opciones que tenían los propietarios y sobre la estabilidad y promoción social de los cultivadores.

\section{La estabilidad creciente de los arrendatarios}

Testimonios indirectos y un número cada vez mayor de estudios sobre el patrimonio de propietarios concretos ${ }^{17}$ muestran que muchos arrendatarios debían permanecer en la tierra durante más tiempo que el establecido en el contrato. Sin embargo, esta cuestión no se ha podido cuantificar hasta ahora. Los obstáculos a la hora de intentarlo son enormes, y guardan relación tanto con la rareza de las fuentes como con las dificultades que implica su tratamiento. La primera de esas limitaciones la hemos superado gracias a la existencia en Gandía (capital de la comarca de la Safor, provincia de Valencia) de una fuente que no tenemos noticia que se conserve en ningún otro lugar: los apéndices al amillaramiento incluyen allí una sección específica para los arrendatarios desde 1864 a 1892. Ello permite conocer todas las modificaciones que se hacían cada año en la titularidad de las explotaciones, pero aparece inmediatamente un segundo obstáculo: hay que seguir, durante 30 años, un conjunto de más de 1.000 nombres. Para afrontar este problema, hemos optado por destacar únicamente los rasgos generales de los cambios que afecten al conjunto de arrendatarios, y por hacer después un estudio más detallado a partir de una muestra parcialmente aleatoria.

\footnotetext{
16 Blasco (1976), p. 29. Modesto (2004), p. 217, relata un caso similar ocurrido en la realidad.

17 Calatayud, Millán y Romeo (1996), (2000), (2002) y (2006); Calatayud, Garrido, Millán y Romeo (2003); Modesto (1998) y (2004).
} 
La estabilidad de los arrendatarios está estrechamente ligada a la debatida cuestión del llamado "arrendamiento consuetudinario". La investigación reciente ha aportado dos importantes novedades al respecto. Por un lado, ha invalidado la pretensión de generalizar al conjunto del territorio esa modalidad de arriendo propia de la Huerta cercana a la ciudad de Valencia. Como ha puesto de manifiesto Modesto ${ }^{18}$, un mismo gran propietario rentista del siglo XIX, con un patrimonio muy diseminado, utilizaba contratos de características muy distintas y estrategias muy diferentes, según la zona donde se encontrara la finca, las tradiciones y posibilidades productivas del entorno, y la presencia de factores sociales locales. Del mismo modo, en 1912, cuando numerosos propietarios del hinterland de la ciudad de Valencia se quejaban de que el arrendamiento hubiera desembocado allí en un menoscabo de "los derechos de la propiedad", el presidente del sindicato católico-agrario de Castellón, un propietario acomodado, reconocía en privado que en la comarca de la Plana el colonato no tenía ningún pretendido "carácter social", y que "actualmente se basa tan solo en la dura ley de la oferta y la demanda"19. La diversidad, pues, era la norma, pero el arrendamiento en el área de Gandía participaba de gran parte de los rasgos propios de la Huerta de Valencia ${ }^{20}$. Se trataba de las dos comarcas donde el regadío estaba dedicado en mayor medida al cultivo de hortalizas.

La segunda novedad ha sido el descubrimiento de que aquella modalidad de arriendo no era, como sugiere su denominación, una pervivencia del pasado sino una práctica construida durante el siglo XIX a partir de condiciones específicas. Gracias, de nuevo, a Modesto ${ }^{21}$ sabemos que a finales del siglo XVIII un gran propietario rentista, el Hospital General de Valencia, compaginaba la maximización de la renta con una intervención intensa en la dirección de sus fincas de la Huerta. A tal efecto, hacía inversiones en ellas, escrituraba con regularidad los contratos y hacía uso en ocasiones de la subasta de arriendos, práctica que implicaba una intensa competencia entre los potenciales cultivadores. La estabilidad del arrendatario era frecuente, pero el Hospital no recurría a la tácita reconducción, sino que escrituraba un contrato corto tras otro. Pero la crisis de principios del siglo XIX supuso una ruptura del anterior modelo, que se consumó cuando a mediados del Ochocientos comenzó una nueva etapa de prosperidad. El Hospital dejó de invertir en la mejora de sus fincas y fue dejando esa responsabilidad en manos de los arrendatarios. Cesó de impartir instrucciones detalladas y precisas sobre las labores, al tiempo que la rotación de cultivos en torno al cáñamo, hegemónica desde el siglo XVIII, retrocedía ante el avance de

\footnotetext{
Modesto (2004).

En carta al jesuita Antonio Vicent, citada en Garrido (1996), p. 218.

Garrido-Juan (1943), pp. 46-47, 49 y 60.

Modesto (1998) y (2004), pp. 175-213.
} 
las hortalizas, muy difíciles de cultivar en caso de no dejar al colono un elevado margen de autonomía. Los contratos dejaron de escriturarse con la frecuencia anterior y se recurrió cada vez en mayor medida a la reconducción anual. Fue entonces, concluye Modesto, cuando emergió el "arrendamiento consuetudinario". La cuestión que queremos plantear es si en la huerta de Gandía, donde se dio una especialización productiva semejante, se produjo el mismo resultado. Lejos de pretender una casuística de las formas de arrendamiento, este interrogante puede clarificar algunos de los postulados de la teoría sobre la explotación indirecta y la elección de contrato.

El espacio agrario situado en torno a la ciudad de Gandía constituye un buen ejemplo de ese mosaico de especializaciones que daba forma a la agricultura intensiva valenciana. La crisis sedera de mediados del siglo XIX fue superada en la comarca con el impulso de la viña dedicada a la producción de pasa ${ }^{22}$. Entre 1862 y 1887, en Gandía, los cereales pasaron del 54 al 35 por 100 de la superficie cultivada, mientras la viña subía del 13 al 34 por 100, con la particularidad de que si en 1862 la viña-pasa ocupaba un 4 por 100 del terreno y la viña-vino un 9 por 100, en 1887 tales porcentajes eran del 33 y del 1 por 100, respectivamente ${ }^{23}$. Mientras España se convertía en "la bodega del mundo", la producción de vino casi desapareció en Gandía debido a la presencia de la pasa que, por razones climáticas, no podía ser cultivada en otras partes y que aquí proporcionaba mayores rendimientos monetarios. Este avance de la agricultura comercial, estimulado por las oportunidades exportadoras, implicaba un aumento de la inversión para la plantación de viñas — de variedades específicas, como la moscatel - y las instalaciones para el secado o el escaldado de las pasas.

Hacia 1900, sin embargo, acabó la época dorada de la pasa española. El proteccionismo norteamericano, con el Arancel McKinley, le dio un duro golpe y la competencia de Grecia y Turquía la expulsó del mercado británico. En 1904, además, llegaba la filoxera. Fue una época muy difícil para una parte de los pequeños propietarios y arrendatarios de la zona ${ }^{24}$. Ya hacía tiempo que estaba en marcha, sin embargo, otra transformación productiva que retornaría la iniciativa al área regada. El cónsul británico afirmaba en 1888: “La Huerta de Gandía está dedicada, más que a lo que habitualmente suele entenderse por agricultura, a una jardinería hortícola con finalidades comerciales" ${ }^{\prime 25}$. La comarca era, después de la Huerta de Valencia, la

\footnotetext{
$22 \quad$ Fontavella (1952), p. 136.

23 Archivo Municipal de Gandía (AMG, en adelante), Padrón de 1861, sig. 1.147; y AMG, Amillaramiento de 1887, sig. 1.151-2.

24 La prensa local aparece cargada aquellos años de noticias sobre confiscación de tierras por impagos de impuestos, sobre los estragos del préstamo usurario o sobre la emigración a América, que en 1906 habría afectado a más de 100 labradores (El Huertano Gandiense, 20/09/1906, p. 3).

25 Foreign Office, Diplomatic and Consular Reports on Trade and Finance, Spain. Report for the year 1888 on the Trade of the Consular District of Barcelona, Londres, Harrison and Sons, 1889, n. 275, p. 2.
} 
principal productora y exportadora de hortalizas, y es probable que la proporción de producto exportada fuera mucho mayor en Gandía que en aquélla. Así, las Huertas de Gandía y Valencia, con su creciente especialización en las hortalizas, adquirían singularidad dentro del regadío valenciano, junto al predominio del naranjo en la Ribera Alta y en la Plana, del arroz en la Ribera Baja o el protagonismo que conservaba el cáñamo en la Huerta de Orihuela.

Las producciones hortícolas no constituían ninguna novedad en Gandía, porque ya en la Edad Moderna había existido una especialización a pequeña escala cuyos artículos eran conocidos en mercados alejados como el madrileño ${ }^{26}$. Hacia 1860, las hortalizas ya se cultivaban de manera habitual por todo el regadío gandiense, pero como un aprovechamiento complementario ${ }^{27}$. En 1883, cuando la ciudad todavía no tenía puerto, se embarcaron desde la playa $2.600 \mathrm{Tm}$ de tomates y 2.000 de cebollas ${ }^{28}$. La mejora de las infraestructuras de transporte daría un impulso definitivo a esas producciones perecederas: en 1884 quedaba completada la conexión ferroviaria con los puertos de Valencia y Denia, y en 1893 se inauguraba el puerto de la propia Gandía. Se ampliaban así las oportunidades exportadoras de una producción que crecía: en 1909 se cosecharon $14.500 \mathrm{Tm}$ de tomates y 13.000 de cebollas $^{29}$.

Tomates, cebollas, pimientos, judías verdes y melones eran los principales artículos. Los cultivadores de la Safor aprovechaban para estas cosechas un microclima más cálido que el del resto de las zonas litorales de la región, que permitía un avance de tres semanas en la maduración de las hortalizas y, por tanto, acceder con ventaja a los mercados europeos cuando los precios eran más elevados. Pero este carácter temprano era también el resultado de las técnicas de cultivo: como mínimo desde el siglo XVIII, para protegerlas del riesgo de heladas, las hortalizas se sembraban en planteles confeccionados dentro de una especie de cajones, a cargo casi siempre de las mujeres campesinas. Cuando se trasplantaban al campo, se las seguía protegiendo del viento y el frío por medio de "invernaderos" confeccionados con setos, cañas o sacos. Se trataba, pues, de un cultivo practicado con exquisitez y que, además del riego, exigía un uso abundante de fertilizantes. Era también muy sensible a los cambios en los mercados: hacia 1890, por ejemplo, los cultivadores de tomates comenzaron a utilizar simiente inglesa, que proporcionaba un fruto más resistente al transporte a larga distancia y se adaptaba mejor a la demanda británica, el principal destino exterior ${ }^{30}$.

Ardit (1993), I, p. 300; Cavanilles (1795), II, p. 145.

Así se indica en el Padrón de 1862.

AMG, sig. 1.651.

El Huertano Gandiense, 27/11/1909, pp. 1-2.

Foreign Office, Diplomatic and Consular Reports on Trade and Finance, Spain. Report for the year 1890 on the Trade of the Consular District of Barcelona, pp. 24-25. 
Los protagonistas de esta próspera agricultura eran, en primer lugar, 1.114 propietarios, que poseían las 2.200 hectáreas cultivadas en Gandía en 1887. El 64 por 100 de ellos tenía menos de una hectárea, pero si tenemos en cuenta la calidad de la tierra $^{31}$, aparecen 943 propietarios (el 85 por 100 del total) con menos de una hectárea de Superficie Equivalente de Regadío, una extensión insuficiente que no permitía la subsistencia de una familia campesina. Si añadimos los desposeídos — cuyo número desconocemos ${ }^{32}$ - , habrá que suponer que en la ciudad y sus alrededores había muchos candidatos a tomar tierra en arrendamiento.

Una muestra de 367 arrendatarios revela que el 64 por 100 no poseía tierra en Gandía y otro 23 por 100 tenía menos de una hectárea. Se ha sumado la tierra que, en su caso, tenían en propiedad a la que trabajaban en arrendamiento, y un 68 por 100 continuaba dentro de la insuficiencia o en sus fronteras. Así pues, un mundo rural con gran capacidad de innovación y de respuesta a los estímulos del mercado era, también, un mundo poblado por muchos propietarios minúsculos y muchos arrendatarios sin tierra propia. Todos ellos tenían que completar los ingresos obtenidos en sus explotaciones trabajando como jornaleros o en la industria doméstica ${ }^{33}$. La participación como cultivadores en el mercado de tierras se vinculaba mayoritariamente, por tanto, a la precariedad de la situación de partida. La aspiración a una mayor estabilidad debía de estar muy presente en las estrategias de unos sectores sociales que no tenían otra manera de eludir la condición de jornaleros. Mientras tanto, el grueso de la tierra arrendada era propiedad de unas escasas 88 personas poseedoras de más de 5 hectáreas (eran el 5 por 100 de los propietarios y controlaban el 56 por 100 de la superficie).

Para unos años antes, hacia 1860, podemos conocer la totalidad del universo de los arrendatarios: en esa fecha estaba arrendada el 43 por 100 de la tierra cultivada y era llevada por 870 colonos. En realidad, el arrendamiento afectaba al 75 por 100 del regadío de Gandía y al 30 por 100 de su secano. ${ }^{34}$ El Cuadro 1 permite realizar otra aproximación a este sector social. Unos dos tercios de los colonos cultivaban en arrendamiento superficies reducidas, inferiores a una hectárea, pero también había un grupo restringido, aunque significativo, que trabajaba más de 2 hectáreas, una superficie de cierta entidad si estaba en el área regada, aunque estas explotaciones mayores eran casi siempre de secano.

Para ello hemos ponderado la superficie en función de los ingresos monetarios medios proporcionados por cada tipo de tierra — regadío, marjal y secano- y hemos reducido toda la extensión a Superficie Equivalente de Regadío. Todos estos datos proceden del Amillaramiento de 1887.

32 Gandía tenía 10.000 habitantes en 1900, y la comarca de la Safor, 60.000.

33 Que podía ser también de carácter agrario, porque sabemos que los planteles que cuidaban las mujeres estaban en parte destinados a ser vendidos a hortelanos de las comarcas vecinas.

$34 \quad$ El área irrigada se extendía en esos momentos por unas 780 hectáreas, y el secano por otras 1.390. 
CUADRO 1

CARACTERÍSTICAS DE LOS ARRENDATARIOS DE GANDÍA HACIA 1860

\begin{tabular}{ccccccc}
\hline $\begin{array}{c}\text { Hectáreas por } \\
\text { arrendatario }\end{array}$ & $\begin{array}{c}\text { Número de } \\
\text { arrendatarios }\end{array}$ & Porcentajes & $\begin{array}{c}\text { Hectáreas } \\
\text { totales }\end{array}$ & Porcentajes & $\begin{array}{c}\text { Número de } \\
\text { parcelas }\end{array}$ & $\begin{array}{c}\text { Parcelas por } \\
\text { arrendatario }\end{array}$ \\
\hline $\mathbf{0} \mathbf{0 , 5}$ & 351 & 40,0 & 113 & 12,0 & 401 & 1,1 \\
$\mathbf{0 , 5 - 1 , 0}$ & 219 & 25,0 & 161 & 17,0 & 420 & 1,9 \\
$\mathbf{1 - 2}$ & 186 & 21,0 & 262 & 28,0 & 548 & 2,9 \\
$\mathbf{2 - 5}$ & 102 & 12,0 & 297 & 32,0 & 430 & 4,2 \\
$\mathbf{5 - 1 0}$ & 11 & 1,0 & 77 & 8,0 & 85 & 7,7 \\
$>\mathbf{1 0}$ & 1 & 0,1 & 18 & 2,0 & 2 & 2,0 \\
\hline Total & $\mathbf{8 7 0}$ & $\mathbf{1 0 0 , 0}$ & $\mathbf{9 2 8}$ & $\mathbf{1 0 0 , 0}$ & $\mathbf{1 . 8 8 6}$ & $\mathbf{2 , 2}$ \\
\hline
\end{tabular}

Fuentes: AMG, sig. 1.147.

Otra característica del arrendamiento gandiense reflejada en el Cuadro 1 es que, excepto los cultivadores más pequeños, la mayoría de los implicados arrendaba más de una parcela. En estos casos, las parcelas solían pertenecer a propietarios distintos. Cuanto mayor era la extensión cultivada por un arrendatario, más alto era el número de propietarios con los que contrataba. La figura de un gran arrendatario con tierras de un único terrateniente era rara. Y si los arrendatarios tendían a no depender de un solo propietario, los dueños también dispersaban sus cesiones entre un número alto de cultivadores. La figura más habitual correspondía a lo que nos muestran los casos del marqués de Jura Real y de Francisco Morant. El marqués, residente en Madrid, tenía arrendadas 73 hectáreas en 1887, repartidas en 130 lotes, que eran trabajados por 118 personas distintas ${ }^{35}$. Morant, un miembro destacado de la élite local, cedía en 1861 en arrendamiento 10 hectáreas entre 27 cultivadores, el más importante de los cuales apenas cultivaba el 9 por 100 del total. De esta manera, los agentes que intervenían en la producción se multiplicaban, y las relaciones sociales alrededor del mercado de tierras adquirían un carácter multiforme.

¿Cuál era el grado de estabilidad de estos arrendatarios cuando accedían a una determinada parcela? ¿Cómo variaba la distribución de los lotes entre el nutrido

35 Las 73 hectáreas del marqués procedían de 43 fincas. Algunas de éstas eran muy pequeñas (la menor, de 0,17 hectáreas), pero otras eran de una extensión considerable en el contexto del regadío valenciano (cuatro superaban las 5 hectáreas). Si eran grandes no constituían una unidad de explotación, sino que estaban "parceladas" entre una pluralidad de colonos. La mayor finca, de 6,2 hectáreas de regadío, estaba repartida entre 18 arrendatarios. 


\section{GRÁFICO 1}

PARCELAS Y HECTÁREAS QUE CAMBIAN DE ARRENDATARIO CADA AÑO EN GANDÍA, 1864-65/1891-92

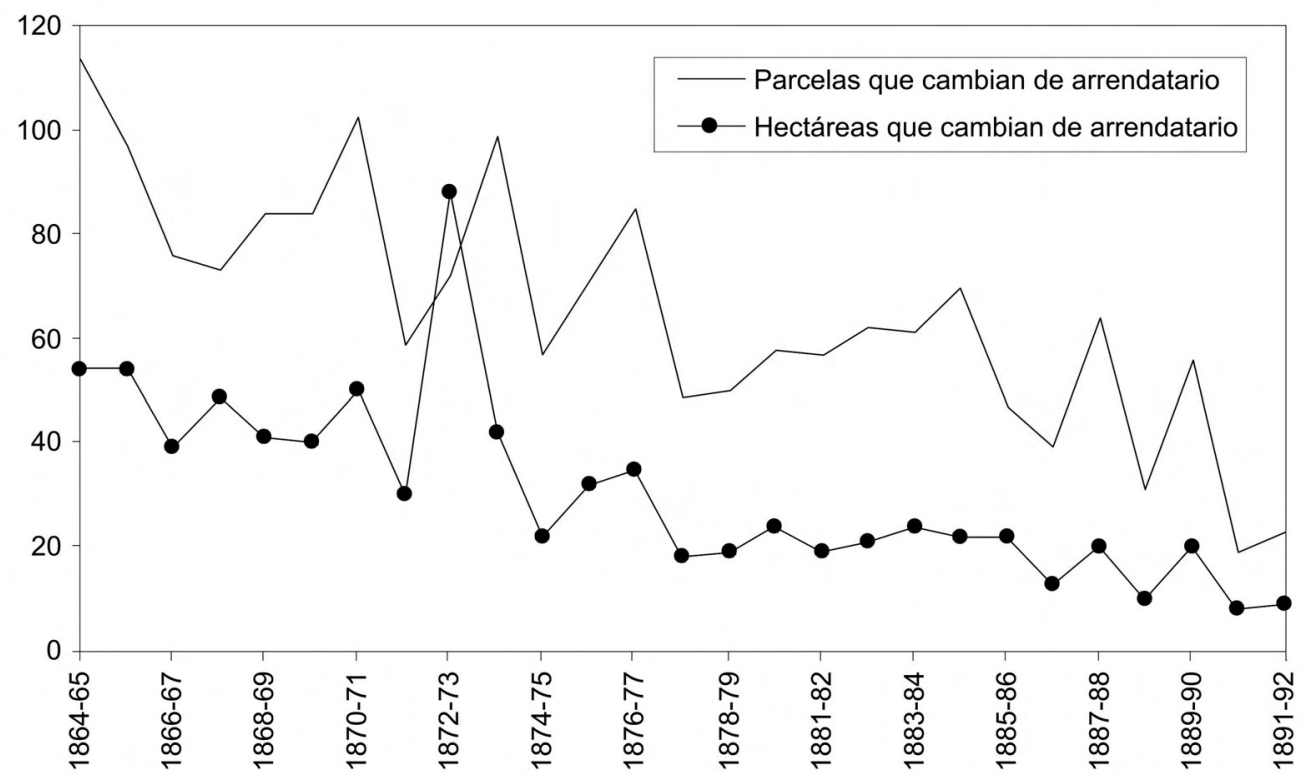

Fuentes: AMG, sig. 1.147, Apéndices al Amillaramiento trasladando los colonatos.

grupo de cultivadores? El Gráfico 1 recoge las parcelas y las hectáreas arrendadas que cambiaron de arrendatario en cada uno de los años transcurridos entre 1864-65 y 1891-92. Tanto en uno como en otro caso, la tendencia es claramente descendente: a medida que transcurría la segunda mitad del siglo XIX, la estabilidad parece ser cada vez mayor. Y hay que tener presente que para los colonos que tenían arrendada más de una parcela (que debían de ser más de la mitad del total), tener que abandonar alguna de ellas no los dejaba sin ninguna tenencia. Ello pasaría, incluso, cuando las diferentes parcelas cultivadas pertenecían a un mismo propietario, ya que era habitual que los contratos se establecieran por separado, de manera autónoma y no sincrónica.

Podemos obtener una visión complementaria si relacionamos los cambios reseñados en el Gráfico 1 con la superficie y con las parcelas que estaban arrendadas al principio del período en cuestión. Esto se hace en el Gráfico 2, donde se observa que, considerado de manera acumulada, entre 1864 y 1892 el cambio de arrendatario afectó a un número de parcelas y hectáreas que equivalía al 84 por 100 de las hectáreas y al 93 por 100 de las parcelas de las que estaban concedidas en renta alrededor de 


\section{GRÁFICO 2}

PARCELAS Y HECTÁREAS QUE CAMBIAN DE ARRENDATARIO EN GANDÍA, 1864-65/1891-92 porcentaje acumulado (100 = parcelas y superficie arrendadas hacia 1860)

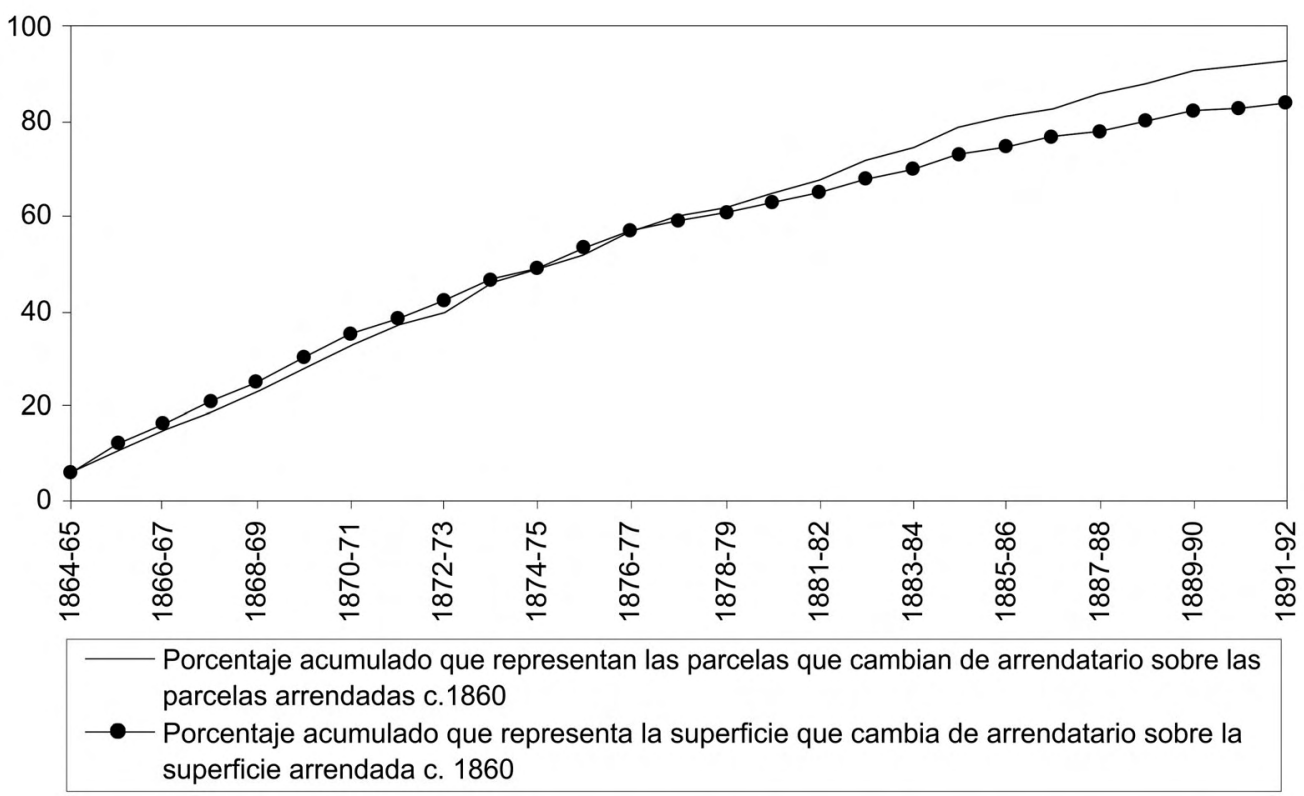

Fuentes: AMG, sig. 1.147 Apéndices al Amillaramiento trasladando los colonatos.

1860. Todo ello parece mostrar, pues, que la movilidad de los arrendatarios era elevada. Pero esta impresión se verá modificada cuando, a continuación, profundicemos en el análisis a través de una muestra de explotaciones ${ }^{36}$.

En principio, hay que introducir tres correcciones a las cifras globales que se acaban de ofrecer. En primer lugar, es seguro que algunas parcelas no cambiaron nunca de titular, mientras que otras lo hicieron muchas veces. En segundo lugar, una parte significativa de los cambios podían tener lugar entre miembros de una misma familia, especialmente de padres a hijos. En estos casos estaríamos ante una interrupción del arrendamiento determinada por el ciclo vital del colono, pero que implicaba la permanencia en la tierra de una determinada familia de cultivadores. Se trataría en

36 En Garrido (1996, pp. 235-241) se utilizaba esta metodología sin profundizar más allá de esta visión general, y se llegaba a la equivocada conclusión de que en Gandía el arrendamiento se caracterizó por la inestabilidad. 


\section{CUADRO 2}

CAMBIOS DE ARRENDATARIOS EN UNA MUESTRA DE PARCELAS DE GANDÍA, 1862-1892

\begin{tabular}{ccc}
\hline Veces & Parcelas & Porcentajes \\
\hline $\mathbf{0}$ & 61 & 59 \\
$\mathbf{1}$ & 27 & 26 \\
$\mathbf{2}$ & 12 & 11 \\
$\mathbf{3}$ & 3 & 3 \\
$\mathbf{4}$ & 1 & 1 \\
\hline Total & $\mathbf{1 0 4}$ & $\mathbf{1 0 0}$ \\
\hline
\end{tabular}

Fuentes: AMG, Padrón de 1862 y Apéndices al Amillaramiento trasladando los colonatos, sig. 1.147.

realidad, pues, de una continuidad reforzada por su carácter intergeneracional. Sólo disponemos de datos fiables para evaluar este fenómeno en 1882-83, cuando el 40 por 100 de los cambios de titularidad, lo mismo de las parcelas que de la superficie, se produjeron como consecuencia de una transmisión familiar. La tercera de las correcciones guarda relación con el hecho de que una parte de los cambios se debían a que el propietario recuperaba la parcela para el cultivo directo. Esta circunstancia marcaba de manera creciente los cambios de arrendamiento registrados ${ }^{37}$.

Para corregir en lo posible las deficiencias de la anterior visión, se ha seleccionado, del Padrón de 1862, una muestra de 104 parcelas y se ha seguido la evolución de cada una de ellas durante los 30 años siguientes ${ }^{38}$. Los resultados quedan recogidos en el Cuadro 2 y en el Gráfico 3. En realidad, la mayoría de parcelas (un 59 por 100) no cambiaron nunca de arrendatario. Pero 16 parcelas (que acapararon más de la mitad de todos los cambios) mudaron de titular más de una vez. Ello nos sugiere un panorama muy diferente al que mostraban las cifras generales: la mayor parte de los arrendamientos gozaban de una larga duración efectiva, ya que entre los que no cambiaron nunca de titular y los que sólo lo hicieron una vez está el 85 por 100 de

37 Sólo disponemos de cifras para 11 años de la serie, pero si en 1864-1866 volvió al propietario el 7 por 100 de las parcelas y de la superficie que cambió de titular, en el quinquenio 1886-1892 lo hizo el 22 por 100 de las parcelas y el 30 por 100 de las tierras.

38 La muestra es aleatoria, pero sólo parcialmente, porque hemos incluido en ella todas las tierras cedidas por un propietario de cierto peso, Francisco Morant, para poder caracterizar el comportamiento de este tipo de terratenientes. 


\section{GRÁFICO 3}

AÑOS DE PERMANENCIA DE CADA ARRENDATARIO EN LA PARCELA

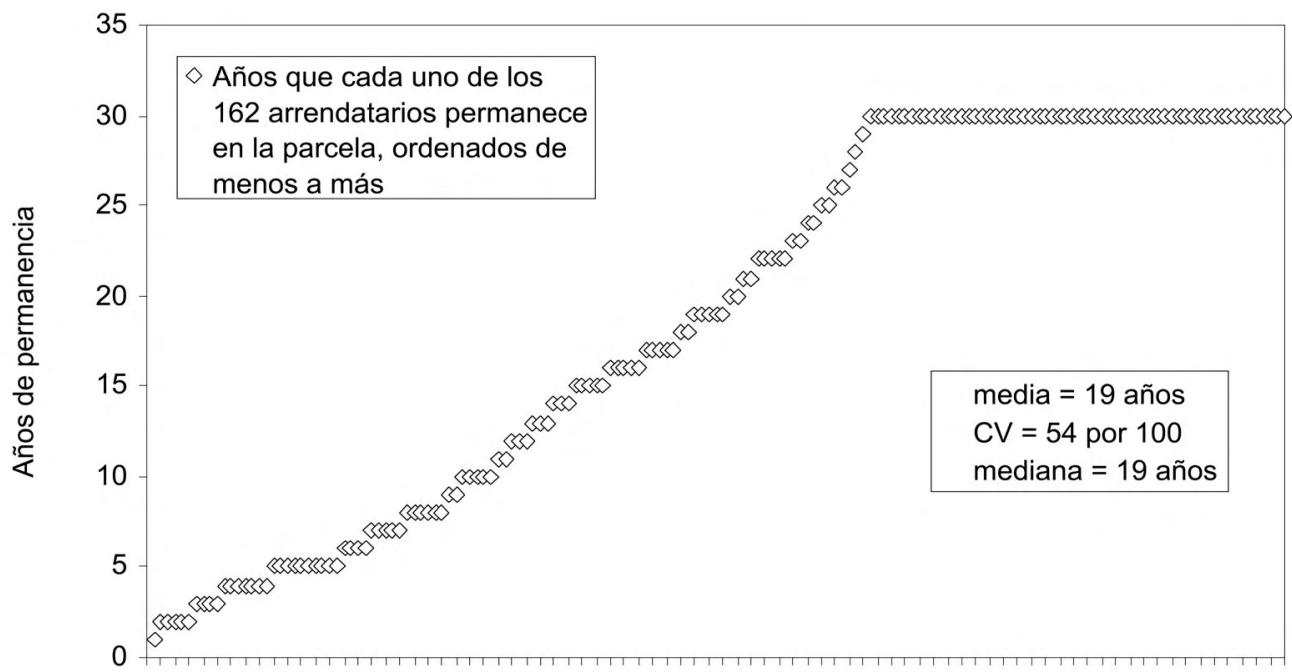

Arrendatarios $(=162)$

Fuentes: Las mismas del Cuadro 2.

las 104 parcelas. En el otro extremo, un número más reducido sí que estaba sometido a una cierta inestabilidad.

Por las 104 parcelas citadas pasaron 162 colonos distintos durante los 30 años considerados. Se ha comprobado cuántos años ocupó cada uno la parcela, se han ordenado los resultados de menos a más y se han representado en el Gráfico 3. La ocupación media, 19 años, es elevada, pero poco representativa, porque sólo coincide con la ocupación efectiva de 5 individuos, mientras que la serie presenta un coeficiente de variación del 54 por 100. Como se observa en la parte derecha del Gráfico 3, 61 personas no abandonaron la tierra durante esos 30 años, pero en la parte izquierda también aparece un número bastante elevado de individuos que sólo estuvieron trabajándola 8,7 o menos años ${ }^{39}$. En cualquier caso, el 48 por 100 de los colonos estuvieron en la parcela durante 20 o más años, lo que puede considerarse un

39 La estabilidad sería mayor de lo que se desprende de estas cifras, ya que el arrendatario podía estar ocupando la parcela desde antes de 1862 y/o continuar en ella después de 1892. 
plazo más que suficiente para estimular al arrendatario a introducir transformaciones y mejoras, y que le permitiría, incluso, rentabilizar la plantación de árboles. Si comparamos con Castilla La Vieja, donde entre 1871 y 1900 la media de permanencia de los arrendatarios se situaba en algún lugar entre los 3,6 y los 8,4 años, el contraste es evidente ${ }^{40}$.

\section{La indemnización de las mejoras}

Si el arrendatario se comportaba como se esperaba de un "buen labrador", cuando abandonaba la tierra dejaba en ella una serie de mejoras. Sin ellas, la finca valdría menos en venta. ¿Había de indemnizarlo el amo del terreno? ¿A quién pertenecían en realidad las mejoras? En todas partes, pero de manera muy especial en una agricultura de las características de la valenciana de regadío, la cuestión de la propiedad de las mejoras estaba muy ligada a la de la estabilidad del colono, a la de las inversiones efectuadas por el dueño en infraestructuras y, en definitiva, a la de quién actuaba como impulsor principal del progreso agrario ${ }^{41}$.

La discusión sobre las mejoras acompañó los debates sobre el arrendamiento en muchos países europeos durante el siglo XIX. En Francia, diversos intentos de introducir en la legislación la obligación de indemnizar a los cultivadores fueron rechazados en el parlamento, donde alguien argumentó que era una medida contraria a los derechos de propiedad ${ }^{42}$. Gladstone también encontró una fuerte oposición en la Cámara de los Lores cuando trató de asegurar por ley este derecho a los arrendatarios de Irlanda ${ }^{43}$, aunque finalmente se aprobara en 1870, y después en 1883, para Inglaterra. En España, mientras el referente fue el código medieval de las Partidas, el propietario tenía que pagar. Durante el siglo XIX no se legisló nada al respecto, y el Código Civil de 1888 no reconoció al arrendatario ningún derecho de indemnización ${ }^{44}$. Durante las primeras décadas del siglo XX, ello se convirtió en una reivindi-

Robledo (1984), p. 178. Carmona y Simpson (2003, p. 127), sin embargo, consideran que los contratos cortos castellanos también eran renovados a menudo por tácita reconducción, lo que se traducía en una gran estabilidad del arrendatario.

41 Es una cuestión a la que hasta ahora se ha prestado en España muy poca atención. Naturalmente, se ha hablado de las mejoras y de los conflictos que han suscitado, pero hasta las aportaciones de Congost (2000) y, sobre todo, de Millán (2006) no se ha puesto de manifiesto su verdadera importancia.

42 Congost (2000), pp. 66-68. "Es declarar que el arrendatario dispone de la cosa del propietario, que transforma y modifica a su voluntad, y que si el propietario no lo reembolsa por el importe de la plusvalía será expropiado de su cosa por su propio arrendatario", citado en la p. 66.

43 Schama (2004), p. 336.

$44 \quad$ Pazos (1908), p. 185. 
cación especialmente cara a los social-católicos, tanto a través del sindicalismo católico-agrario como por obra de diversos diputados, más o menos cercanos a esa corriente, que entre 1918 y 1921 presentaron a las Cortes proyectos de reforma agraria donde se contemplaba la indemnización por mejoras ${ }^{45}$.

Tras la abolición del derecho foral en 1707, el código castellano de las Partidas pasó a ser la norma legal imperante en el antiguo Reino de Valencia. Desde finales del Antiguo Régimen, los propietarios valencianos que querían evitar el pago de las mejoras incluían en el contrato una cláusula con la renuncia del colono a recibirlo ${ }^{46}$, pero da la impresión de haber sido una opción muy variable según los lugares. La mayoría de los contratos contenían esa cláusula en la Huerta de Valencia durante la primera mitad del siglo XIX, mientras que en Orihuela era una práctica poco frecuente $^{47}$.

Para abordar aquí el tema de las mejoras hemos recurrido a dos tipos de fuentes: los testimonios de los contemporáneos y los contratos escriturados. La investigación reciente basada en patrimonios valencianos ha cuestionado la identificación del arrendamiento con absentismo y aversión al riesgo por parte de los propietarios. Los terratenientes rentistas invertían con frecuencia en la mejora de las infraestructuras y, aún explotando de manera indirecta, no renunciaban a asumir cierto papel "empresarial", ya que daban instrucciones precisas al cultivador sobre el modo de trabajar la tierra ${ }^{48}$. El buen cultivo continuaba exigiendo en esos casos que el arrendatario hiciera mejoras. Pero si el propietario no quería o no podía invertir, la cuestión adquiría otra dimensión: las mejoras quedaban exclusivamente a cargo del colono.

Sin embargo, el cultivador sólo afrontaría las mejoras si gozaba de estabilidad o si se le indemnizaba por ellas al final del contrato. Como hemos visto en el apartado anterior, el colono gozó en Gandía, como media, de una elevada estabilidad, creciente a medida que transcurría la segunda mitad del siglo XIX. ¿De qué manera influyó sobre ello el pago (o no pago) de las mejoras? Según una posible interpretación, arrendatario y dueño podrían haber llegado a un acuerdo: aquél renunciaba a cobrar las mejoras, mientras que el propietario, para que pudiera rentabilizarlas, le garantizaba la estabilidad durante un dilatado período. Probablemente es lo que pasó en determinados casos, pero tratar de aplicar este razonamiento de manera generalizada presenta dos inconvenientes. Uno es que, dado que el dueño tenía muchos alicientes para no cumplir con su palabra, el arrendatario querría disponer

\footnotetext{
Garrido (1996), p. 109; Malefakis (1982), pp. 496-497.

Goerlich (1982), p. 203; Millán (2006).

Millán (2006).

Calatayud, Millán y Romeo (1996), (2000), (2002) y (2006).
} 
de alguna garantía que alejara la posibilidad de que le ocurriera lo que al personaje de La Barraca que hemos citado con anterioridad. Existía una fácil solución: firmar contratos largos en lugar de contratos cortos prolongados por tácita reconducción ${ }^{49}$. Pero no se hizo ${ }^{50}$. El segundo inconveniente es que los contemporáneos dan una interpretación totalmente opuesta: no es que los propietarios concedieran estabilidad a cambio de no pagar mejoras, sino que los arrendatarios consiguieron la estabilidad como consecuencia de que los dueños sí tenían que pagarlas. En otras palabras: muchas veces la indemnización llegaba a ser de tal magnitud que los propietarios tenían problemas para satisfacerla $\mathrm{y}$, aunque quisieran, no podían expulsar a unos colonos que, como resultado de poseer las mejoras, se habían convertido en "semipropietarios de hecho" de las fincas que trabajaban ${ }^{51}$.

En ocasiones se dijo, como en 1869 el cónsul inglés en Alicante, que las mejoras se pagaban mediante cantidades establecidas por la costumbre para cada tipo de intervención que hubiera hecho el cultivador ${ }^{52}$. Pero, de manera mucho más frecuente, lo que se decía es que, al finalizar efectivamente el contrato, dos peritos escogidos por las partes calculaban en cada caso el valor de las mejoras (o de las "peoras") introducidas por el arrendatario. En algunos lugares, la costumbre establecía el derecho del arrendatario saliente a llevarse consigo la "flor de la tierra" (terra flor); es decir, la capa superficial de tierra rica en humus y mimada por las constantes labores. Pero como ello desmerecería enormemente la finca, se dejaba la "flor de tierra" en su sitio y se daba una compensación monetaria al colono saliente: lo que hacían los peritos era valorar la "flor de tierra" estableciendo la cuantía de la compensación sustitutiva ${ }^{53}$. Naturalmente, si se habían plantado árboles o construido equipamientos, las mejoras a valorar no estaban sólo en el suelo, pero tiene un alto valor simbólico que esta interpretación establezca una equiparación entre las mejoras y la "flor de tierra": si ésta pertenecía al colono, era él el dueño de la "fertilidad" de la tierra.

Supuestamente, estas prácticas regían a finales del siglo XIX e inicios del XX en todas las comarcas valencianas de regadío, pero era en la Huerta de Valencia y en Gandía donde se utilizaban al máximo, siendo uno de los componentes fundamentales del "arrendamiento consuetudinario" de esos lugares. Precisamente a propósito

49 Lo que, de todas maneras, no haría desaparecer los problemas, a los que ya se ha hecho alusión, relacionados con el éxito de la estrategia del "ojo por ojo".

50 En el siglo XIX, sólo el 0,3 por 100 de los contratos valencianos escriturados se firmaron por más de 12 años. Pons (1990), p. 183.

51 Ruiz (1991, pp. 95-96) relata con cierta extensión un caso que apunta claramente en esa dirección.

52 Después de citar otros casos, añadía: “También es práctica común rembolsar al arrendatario saliente con un cuarto de cada frutal, olivo o algarrobo que haya plantado de más sobre los que recibió, con la condición de que tenga tres años y el ramaje formado". Foreign Office, Report respecting the tenure of land in the province of Alicante, 1869 , p. 51.

53 Monforte (1922), p. 15; Garrido-Juan (1943), p. 60. 
de Gandía, en 1908 se afirmaba que la práctica — presuntamente "inmemorial” — de indemnizar por mejoras habría "puesto coto a los desahucios e impedido que las rentas sean tan elevadas como en otros puntos de Valencia y Alicante", ya que

"cuando intenta el propietario despedir al colono al terminar el contrato, justiprecian los peritos las mejoras hechas por el arrendatario, y como casi siempre importa más el valor de éstas que el que sin ellas tendría la finca, el dueño se ve precisado a dejar en paz al colono cultivando su huerta" ${ }^{54}$.

Algunos testimonios afirman que, tanto en la Huerta de Valencia como en la de Gandía, no era excepcional que las mejoras ascendieran al 50 por 100 del valor en venta de la finca ${ }^{55}$ (o más exactamente al 50 por 100 de lo que valdría la finca en caso de venderse sin arrendatario, porque cuando estaba ocupada por un colono nadie estaba dispuesto a pagar por ella más de la mitad de aquel precio). Es difícil saber si se trata de una exageración. Cuando, por una u otra razón, los contratos escriturados valoran las mejoras, se consigna casi siempre una cifra superior a la de la renta anual. De los contratos analizados, la indemnización alcanzaba el mayor valor en uno en el que se pagaban 78 escudos anuales de renta y las mejoras ascendían a 300 escudos $^{56}$. Capitalizando la renta al 4 por $100^{57}$, las mejoras supondrían el 15 por 100 del valor de la tierra, un porcentaje considerable, pero, evidentemente, mucho más bajo que el 50 por 100 .

Como prueba de la gran capacidad de decisión sobre la gestión de las fincas alcanzada por el colono, los contemporáneos mencionan los pagos en concepto de l'estrena (también llamada les passes) ${ }^{58}$. Era la suma que el arrendatario entrante daba al saliente cuando, por voluntad propia, éste decidía marcharse y, con el consentimiento del dueño, traspasaba a otra persona el cultivo de la parcela. Era algo, se dice, bastante habitual en el regadío valenciano, pero la singularidad de la Huerta de Valencia y de Gandía era que allí l'estrena era de una cuantía especialmente elevada, llegando a alcanzar la mitad del valor en venta de la finca ${ }^{59}$. Tal pago significaba dos cosas. Por una parte, la venta por el antiguo arrendatario a su sucesor de las mejoras

\footnotetext{
$54 \quad$ Morán (1908), p. 39.

55 Burriel y Oller (1929), p. 118; Garrido-Juan (1943), pp. 46-47.

56 AMG, Protocolos, DA, García, 1870, f. 246.

57 Parece una capitalización muy alta, pero es la que se indica en Ministerio de Fomento (1918), p. 367, como media para el regadío de la provincia de Valencia.

58 Según el Diccionari català-valencià-balear, una estrena es la gratificación que se da a alguien para celebrar el comienzo de una cosa, y también aquello que se da además del precio contratado (aguinaldo). Passa (singular de passes) no figura con esa acepción en ningún diccionario, pero se refiere a la gratificación dada por la transmisión de algo. 


\section{CUADRO 3}

EVOLUCIÓN DE LA OBLIGACIÓN DE PAGAR MEJORAS EN LOS CONTRATOS

ESCRITURADOS EN GANDÍA, 1850-1900

\begin{tabular}{cccc}
\hline \multirow{2}{*}{ Años } & Contratos escriturados & \multicolumn{2}{c}{ Contratos que excluyen el pago de mejoras } \\
\cline { 3 - 4 } & & Número & Porcentajes \\
\hline $\mathbf{1 8 5 0}$ & 16 & 1 & 6 \\
$\mathbf{1 8 6 0}$ & 22 & 2 & 9 \\
$\mathbf{1 8 7 0}$ & 14 & 3 & 21 \\
$\mathbf{1 8 8 0}$ & 6 & 2 & 33 \\
$\mathbf{1 8 9 0}$ & 4 & 3 & 75 \\
$\mathbf{1 9 0 0}$ & 7 & 1 & 14 \\
\hline
\end{tabular}

Fuentes: AMG, Protocolos Notariales.

que poseía. Simultáneamente, y dado que ello requería de la aquiescencia del propietario, el reconocimiento por parte de éste de que la "fertilidad del suelo" pertenecía ahora al nuevo cultivador.

¿Hasta qué punto se ven estas afirmaciones corroboradas o desmentidas por los protocolos notariales? La respuesta no puede ser tajante porque, como en otros muchos lugares, los contratos de arrendamiento escriturados eran una exigua minoría $^{60}$. En el Cuadro 3 se recogen los datos que hemos obtenido para una muestra de seis años que incluye toda la segunda mitad del siglo XIX. En la única medición sobre el fenómeno efectuada hasta ahora, Millán ha detectado una tendencia bastante marcada de los propietarios valencianos, durante las últimas décadas de esa centuria, a dejar especificado en los contratos realizados por medio de escritura pública que no pagarían mejoras ${ }^{61}$. En el Cuadro 3 se observa lo mismo para Gandía (con la excepción de 1900) si nos fijamos en los porcentajes, pero las cifras absolutas son tan reducidas que obligan a considerar con mucha prudencia las conclusiones que se obtengan de ellas. En cualquier caso, teniendo en cuenta que en Gandía el derecho del arrendatario a recibir mejoras parece haber estado sancionado por la costumbre, habría más bien que pensar que, si los propietarios hubieran querido no pagarlas, habrían recurrido en mayor medida a escriturar los

60 Hemos calculado que, hacia 1870, en Gandía se escrituraba anualmente menos del 1 por 100 de los contratos de arrendamiento que se iniciaban o renovaban. Carmona y Simpson (2003, p. 128) indican algo similar para Castilla.

61 Millán (2006). 
contratos, y que si apenas se escrituraban es porque, mayoritariamente, sí se pagaban las mejoras. De hecho, las cifras del cuadro muestran que, con variaciones temporales, la mayoría de los arrendatarios podían esperar cobrar por las mejoras introducidas.

Los contratos confirman también que la indemnización, cuando aparecía explícita, vinculaba de diferentes modos a los sujetos de la relación de arrendamiento. Una condición muy frecuente era que el colono entrante tuviera que abonar, al margen de la renta pactada, las mejoras que la finca contuviera en el momento de hacerse cargo de ella ${ }^{62}$. El beneficiario del pago podía ser, bien el colono que dejaba la tierra $^{63}$, bien el propietario de la misma. Se trataba, pues, de dos posibilidades con implicaciones diferentes. El primer caso confirma la existencia del pago de l'estrena entre arrendatarios, que destacaban los contemporáneos. El segundo muestra una práctica que, según Monforte, era propia de la Huerta de Gandía: las mejoras pertenecían al arrendador, que las vendía temporalmente al cultivador a cambio de una suma que sería devuelta "al arrendatario, o a sus sucesores, al terminarse, por cualquier causa, el arrendamiento"64. Dado que el dueño de la tierra tenía en todo momento la opción de indemnizar al arrendatario y volver a convertirse en el "propietario único" de su propia finca, el cambio de propiedad de las mejoras realizado entre arrendatarios mediante el pago de l'estrena parece indicar una falta de interés del terrateniente en la inversión y en la dirección de la explotación. Sin embargo, es más probable que respondiera al convencimiento de que, en una agricultura como la gandiense, donde los cultivos hortícolas tenían un protagonismo en ascenso, convenía a las dos partes que las mejoras fueran del arrendatario.

De hecho, la misma lógica parece presidir el otro caso. Cuando las mejoras pertenecían al terrateniente, ¿por qué las vendía al colono, con el compromiso de recomprarlas cuando éste abandonara la finca? Todo parece indicar que ello tenía una doble finalidad. En primer lugar, aumentaría así el interés del colono no sólo en que los rendimientos fueran altos a corto plazo, sino también en que, a largo plazo, la "fertilidad" de la finca no desmereciera, ya que le pertenecía como consecuencia de una compra. Ciertamente, ello también sucedía cuando el colono compraba las mejoras al anterior arrendatario. Sin embargo, en segundo lugar, si la transacción era con el propietario, éste podía penalizar económicamente al colono — cuando al final del contrato le recomprara las mejoras- si la finca estaba en peor estado que

\footnotetext{
62 Parece cierta, pues, la afirmación de que “...el capital representado por las mejoras no suele entrar a formar parte del retribuido por el arrendatario al pagar el precio del arrendamiento". Monforte (1922), p. 16.

63 "Que sea de su cuenta [del nuevo colono], al entrar en el arriendo, entenderse con el abono de las mejoras con el arrendatario saliente". AMG, Protocolos, A768, Pastor, 1850, f. 605.

64 Monforte (1922), p. 16.
} 
al hacerse cargo de ella; en el caso de l'estrena, el arrendatario también sufriría una penalización económica — porque l'estrena que le pagaría el colono siguiente sería menor que la que él desembolsó-, pero el terrateniente no podría resarcirse de la depreciación experimentada por su propiedad. La venta de las mejoras actuaba en este caso, pues, como una garantía de buen cultivo dada por el arrendatario al arrendador. De todas maneras, no dejaba de ser un procedimiento peligroso para éste, porque era una suma ${ }^{65}$ que, tarde o temprano, tendría que devolver al colono si quería recuperar la "propiedad plena" de su terreno, con la posibilidad de que, por carecer de liquidez o por cualquier otra razón, en el futuro pudiera tener problemas para hacerlo. Especialmente si, como en efecto sucedía, la costumbre daba al arrendatario la potestad de ir aumentando la cuantía de la fianza —al margen de la voluntad del terrateniente- mediante un cúmulo de pequeñas, pero constantes, atenciones prodigadas a la tierra. Como veremos, a la larga los resultados serían los mismos en todos los casos: la aparición de un cierto derecho de propiedad del arrendatario que se materializaría en una suerte de "compra silenciosa" de la tierra por parte del mismo.

Precisamente para minimizar ese peligro, el propietario trataba a menudo en los contratos escriturados $-\mathrm{y}$, seguramente, por eso los escrituraba- de poder modular, sin anularla, la iniciativa del arrendatario. Por ejemplo, en varios contratos que no incluían la cláusula para eximir del pago de mejoras, se establecía la obligación del colono de pedir permiso para hacer cualquier "innovación", que en caso contrario no sería retribuida ${ }^{66}$. En bastantes ocasiones se explicitaba en el contrato el tipo de mejoras que serían abonadas y las que quedaban excluidas. Así, diversas escrituras coinciden al señalar que las mejoras pagadas sólo serían "las que acaso hubiese en el suelo de la tierra"67. En estos casos el ámbito de aplicación era bastante amplio y comprendía tanto las llamadas "cosechas pendientes" (dejar sembrados de zanahorias o alfalfa, que hubiera trigo para segar, etc.) como las labores preparatorias de la tierra (del tipo labrar el barbecho o incorporar fertilizantes), e incluso cuestiones aparentemente menores, como dejar un cañaveral en buen estado ${ }^{68}$. Por el contrario, solía tenerse buen cuidado en especificar que la obligación de plantar árboles, siempre que los plantones los pagara el propietario, iba acompañada de la renuncia del arrendatario a ser indemnizado, aunque en muchas ocasiones era una

65 Que no se depreciaría por efecto de una posible inflación, ya que lo que se pagaba al entrar y al salir un colono era la valoración de los peritos.

66 “[El arrendatario] no podrá tampoco hacer innovaciones en la finca en plantaciones ni de ningún otro modo sin permiso de quien tenga derecho para darlo, y si lo hiciere sin este requisito y fuera mejorando la finca, cederá ello en beneficio de ésta", AMG, Protocolos, DA932, Sanz, 1880, f. 661.

67 AMG, Protocolos, DA42, Arias, 1860, f. 912.

68 AMG, Protocolos, DA912, Sanz, 1870, f. 2.045. 
renuncia sólo parcial, porque sí podría pedir indemnización por las "mejoras que existan en el suelo"69. Resulta una cautela bien comprensible, sobre todo cuando el árbol era el naranjo, porque una finca plantada de naranjos, en plena producción y óptimo estado, fácilmente podía tener un precio por unidad de superficie dos o tres veces mayor que el de las parcelas vecinas de regadío dedicadas a otros aprovechamientos: un arrendatario al que se dejara plantar naranjos sin cortapisas tenía muchas probabilidades de haberse convertido, a los diez o quince años de efectuar la plantación, en "más dueño" de la finca que el propietario del terreno, aunque fuera exclusivamente éste quien la tuviera escriturada a su nombre en el Registro de la Propiedad ${ }^{70}$. Por otra parte, en los contratos se podía limitar la cantidad que debía ser abonada por mejoras, como en un caso en que el propietario se compromete a dar al arrendatario exactamente lo mismo que éste le hubiera pagado al hacerse cargo de la finca, sin tomar en consideración las mejoras que hubiera introducido de más por su cuenta ${ }^{71}$.

En los contratos escriturados había, pues, múltiples formas de tratar esta cuestión; de manera que se hace difícil defender la idea de que se trataba de documentos estereotipados. Los sujetos que intervenían en el arrendamiento adaptaban el reembolso de las mejoras a condiciones específicas que unas veces podemos intuir y otras se nos escapan. Pero lo que resulta claro es la importancia que la negociación sobre las mejoras tenía en las preocupaciones de los propietarios y los colonos reunidos en los despachos de los notarios.

Por último, hay que tener presente que la multitud de transacciones en torno a la remuneración del esfuerzo del cultivador era simultánea a otros pactos y conflictos constitutivos de la relación de arrendamiento, como, por ejemplo, el importe de la renta o la actitud ante los atrasos en el pago de la misma. Aunque todo ello queda fuera del presente trabajo, sólo quisiéramos referirnos brevemente a la cuestión de los atrasos. Los datos referidos a un patrimonio de la zona ${ }^{72}$, entre los años 1884 y 1900, sugieren que el pago de la renta (cuyo importe no varió durante todo este período, lo que seguramente significa que aumentó en términos reales) estaba sujeto a retrasos

AMG, Protocolos, A768, Pastor, 1850, f. 601; A952, Sanz, 1890, f. 272.

70 La alternativa en estos casos consistía en restringir al máximo la iniciativa del cultivador. Pero si el propietario hacía eso también estaba renunciando a muchas de las ventajas que presenta el arrendamiento sobre la explotación directa en agriculturas que requieren mucho trabajo especializado, atenciones y saberes prácticos. Como el arrendamiento presentaba en tal caso pocos atractivos para los propietarios, prescindieron de él cuando, durante los años finales del siglo XIX, se consolidó el cultivo del naranjo y, hacia 1900, ya eran excepcionales los naranjales en plena producción dados en arrendamiento.

71 AMG, Protocolos, Aragonés, 1880, s/p.

72 Se trata del propietario, residente en Valencia, Vicente Calatayud. Archivo del Reino de Valencia (ARV, en adelante), Fondo Calatayud-Enríquez de Navarra, 27-3 al 27-15. Sus tierras, con una extensión de ocho hectáreas, estaban en Beniarjó y eran cultivadas por 22 arrendatarios. 
importantes, y que éstos experimentaban, a lo largo del tiempo, ciclos al alza y a la baja $^{73}$. En los peores años, en torno al 60 por 100 del importe de las rentas quedaba sin pagar en el plazo estipulado, pero, en cualquier caso, se trataba de un fenómeno habitual: durante un lapso de 17 años, en sólo dos ocasiones los retrasos bajaron del 20 por 100. El propietario toleraba estas demoras, puesto que sólo en 1901 amenazó a los arrendatarios con el desahucio. En la medida en que estos valores puedan generalizarse, el fenómeno resulta significativo porque nos indica que los cambios y la mejora de la producción no se hacían sin dificultades. Las producciones en ascenso estaban sujetas a nuevas vulnerabilidades ${ }^{74}$, y el proceso de sustitución de cultivos generaba incertidumbres y caídas coyunturales de los ingresos, especialmente dañinas para las economías campesinas cercanas a la precariedad. Pero, nuevamente, ello nos permite hacer una reflexión sobre el papel central que, seguramente, jugaron las mejoras.

En un congreso de Acción Social Católica, en el que se exaltó al máximo la supuesta colaboración entre clases sociales en el mundo rural valenciano, dos personajes señeros de la derecha confesional regional, Facundo Burriel y Manuel Oller, mencionaron "la seguridad que tiene el dueño en el cobro, aunque no puntual, de la renta, puesto que el arrendatario entrante se carga los descubiertos del saliente" ${ }^{\prime \prime 5}$. Lo de la armonía de clases era un mito conservador, pero lo de los retrasos no. En un amplio análisis de contratos de arrendamiento valencianos firmados mediante escritura pública, Pons señala las numerosas referencias que aparecen a deudas de anteriores colonos asumidas por sus sucesores ${ }^{76}$. Pero hay que tener presente que, si antes hemos dicho que las mejoras actuaban como una fianza a favor de la "fertilidad", también eran una garantía del pago de la renta: si se acumulaban muchos impagos y el arrendatario era expulsado por insolvencia, el arrendador se apropiaba de las mejoras y no perdía en realidad todos los atrasos, sino que "recuperaba propiedad"; si el arrendatario no podía afrontar la deuda y decidía traspasar la parcela,

73 Un terrateniente mucho mayor de la zona, el marqués de Jura Real, también tuvo numerosos problemas para cobrar la renta en los difíciles años de finales del siglo XIX (Mezquita, 2005, pp. 63-64). Su administrador lo atribuía en parte a una sucesión de desastres meteorológicos, pero en el Amillaramiento de Gandía de 1887 se habla de "la depreciación que han sufrido los productos de la tierra en esta región desde $1885^{\prime \prime}$.

74 En junio de 1899, escribía el administrador del patrimonio: "Con la helada general que sufrieron las cosechas tempranas no ha empezado a animarse verdaderamente el mercado de hortalizas hasta principios de la última semana, y este retraso influirá en que las ventas sean en peores condiciones que hubieran resultado si las cosechas hubieran salido a su tiempo; otra de las causas que influirán en que el año resulte muy deficiente es la negrilla, que ha atacado algunos campos y que en las primeras remesas puso a pique de desacreditar este mercado por las malas condiciones en que llegó el fruto a Inglaterra". ARV, Fondo Calatayud-Enríquez de Navarra, 27-32.

75 Burriel y Oller (1929), p. 118.

76 Pons (1990), p. 181. 
utilizaría l'estrena para llegar a un acuerdo con el nuevo cultivador, que en ocasiones pasaba a ser dueño de las mejoras a cambio de hacerse cargo de las atrasos. Las mejoras, en definitiva, eran susceptibles de ser compradas, vendidas y canjeadas ${ }^{77}$. Formaban parte, por tanto, de un conjunto más amplio de transacciones entre los propios cultivadores - deudas, ayudas mutuas, apoyos familiares- que escapan a los contratos escritos, pero que debían de ser importantes.

\section{Conclusiones}

La teoría de los contratos agrarios ha puesto un énfasis especial en las condiciones que explican la elección entre arrendamiento, aparcería y cultivo con asalariados ${ }^{78}$. Para determinar la eficiencia relativa de cada tipo de contrato es bastante usual circunscribir los objetivos generales, tanto del principal como del agente, a la maximización de las ganancias y a la minimización del esfuerzo y del riesgo. Aunque no de manera explícita, este horizonte teórico ha estado presente en algunas de las cuestiones tratadas en el presente trabajo. Sin embargo, no se ha tratado de aplicar ninguno de los modelos habituales, sino que el objetivo ha sido profundizar en aspectos a los que el marco general teórico presta poca atención y que resultan esenciales para comprender los efectos del cultivo indirecto sobre el desarrollo agrario.

Si asumimos que el objetivo general del propietario consiste en maximizar los ingresos, es preciso matizar enseguida que esa aspiración se manifiesta, en la práctica, a través de otros objetivos más específicos que, por resultar a menudo contradictorios entre sí, plantean la necesidad de elegir. Un propietario que cede tierra en arrendamiento se encuentra, en principio, ante cuatro metas: a) maximizar la renta percibida; b) evitar que el arrendatario esquilme la tierra, lo que desvalorizaría el capital; c) gozar de plena libertad para expulsar al arrendatario cuando le convenga, lo cual implica que éste no adquiera ningún "derecho" de permanencia sobre la parcela que, a efectos prácticos, lo convierta en "semi-propietario"; y d) obtener una revalorización de la tierra, gracias a un proceso continuado de mejoras.

77 Los protocolos ofrecen numerosos ejemplos de ello. Un contrato firmado en 1884 por 4 años, que se renovó dos años por tácita reconducción, volvió a ser escriturado en 1890 para dejar constancia de que, como el arrendatario debía 1.001 pesetas, se le renovaba el contrato sin que ahora tuviera derecho a mejoras (AMG, Protocolos, A951, Sanz, 1890, f. 154). En otro contrato, el arrendatario se hace cargo de los impagos del anterior colono, pero éste le cede cosechas pendientes y mejoras (AMG, Protocolos, DA, 383, García, 1870, f. 246).

78 Otsuka, Chuma y Hayami (1992); Hayami y Otsuka (1993). Una crítica a la noción de eficiencia económica que se maneja en esta literatura en Bhaduri (1999), pp. 17-76 y 88-89. 
En la práctica, sin embargo, los modos de materializar estas aspiraciones pueden interferir entre sí. Por ejemplo, si el propietario pretende maximizar la renta, optará por contratos cortos que le permitan cambiar de arrendatario cuando aparezca otro dispuesto a pagar más. De esa manera quedan garantizados los objetivos a) y c), pero no se conseguirán b) ni d). El arrendatario tenderá a esquilmar la tierra (y si el propietario quiere evitarlo tendrá que incurrir en elevados costes de transacción) y evitará invertir en la mejora de la explotación. ¿Cómo conseguir simultáneamente que la renta sea lo más elevada posible, que la tierra se revalorice como consecuencia de un proceso de inversión permanente y que se pueda prescindir a voluntad del colono? Además, la necesidad de elegir cobra una mayor complejidad cuando la observamos en una agricultura intensiva en la que existen muchas posibilidades de mejorar el cultivo variando así la función de producción. Todos éstos eran dilemas reales a los que se enfrentaban los propietarios arrendadores.

La exploración realizada en las páginas anteriores sobre la estabilidad de los arrendatarios y la indemnización de las mejoras ha mostrado que la práctica del arrendamiento resultó inequívocamente favorable a la innovación en el cultivo y contribuyó, por tanto, al desarrollo agrario que experimentó la comarca de Gandía desde las décadas centrales del siglo XIX. Sin embargo, la dinámica abierta por ese modo de practicar el cultivo indirecto acabaría modificando las relaciones sociales. El pago de las mejoras aparece como una práctica bastante habitual. Su sentido era reconocer al arrendatario la propiedad de los cambios y las inversiones con el objetivo de incentivarlo a realizarlas, evitando reconocerle derecho alguno a la estabilidad. Pero, a medio plazo, los resultados fueron totalmente distintos: el empleo continuado de grandes cantidades de trabajo permitía al arrendatario realizar una especie de "compra silenciosa" de una tierra de la que, de hecho, se convertía en semi-propietario, porque para expulsarlo el propietario tenía que abonar una suma que podía representar la mitad del precio que la tierra habría tenido en caso de estar libre de arrendatario. A la larga, pues, el pago de las mejoras, concebido como una alternativa al reconocimiento de la estabilidad, tendió a significar estabilidad para el arrendatario, porque el dueño no siempre disponía o quería gastar el líquido necesario para expulsarlo.

Esta dinámica peculiar de la relación de arrendamiento estaba totalmente vinculada a la especialización productiva que más se expandía en la zona: las hortalizas. De igual modo que sucedía en la Huerta de Valencia, estos cultivos, que requieren muchas atenciones, cierta cualificación del labrador y operaciones dispersas y discontinuas, eran difíciles de reglamentar en los contratos de arrendamiento. Por lo mismo, la inversión directa del propietario resultaba más problemática que en cualquier otra producción, debido a la dificultad de asegurarse de que el cultivador haría un buen uso de aquélla. El riesgo moral era elevadísimo en este caso. El resultado fue que los cultivadores tendieron a actuar de forma notablemente autónoma. Al con- 
trario de lo que era usual en otras áreas del regadío valenciano, aquí los contratos escriturados apenas especificaban las labores que el arrendatario debía realizar. Propietarios rentistas que, a finales del siglo XVIII, ejercían un gran control sobre el cultivo de sus fincas, con el paso del tiempo tendieron a abandonar el papel de "empresarios" y se desentendieron cada vez más de la inversión ${ }^{79}$. Paradójicamente, el progreso agrario, en el caso de la especialización hortícola, exigió la disminución de la iniciativa del propietario y la concesión de una amplísima autonomía a los arrendatarios.

No se trata de afirmar ningún determinismo de la orientación productiva sobre las características de la relación de arrendamiento, pero cada opción agraria tenía repercusiones diferentes sobre la organización de la producción. En otras zonas, como las que optaron por la especialización naranjera, la evolución fue diferente: a finales del siglo XIX aumentó el número de contratos escriturados en los que se especificaba que el arrendatario no tenía derecho a cobrar mejoras. Dejar esas plantaciones totalmente a cargo del arrendatario podía incrementar de manera extraordinaria la cantidad que el dueño tendría que abonar en el futuro si quería "recomprar la plena propiedad" de su tierra, y lo que acabaron haciendo los propietarios, cuando la naranja se consolidó como opción productiva, fue pasar a la explotación directa ${ }^{80}$. Pero, en virtud de la path dependence, ello resultaba cada vez más difícil en otras zonas a medida que el tiempo transcurría, y Gandía y la Huerta de Valencia fueron las dos comarcas valencianas de regadío donde el naranjo avanzó de manera más lenta.

Aquella capacidad del sistema agrario local para innovar y prosperar permitió que, salvo coyunturas excepcionales como la de los años finales del siglo XIX o la del derrumbe de la pasa a principios del XX, los propietarios contemplaran con cierta seguridad el cobro regular de una renta remuneradora. A largo plazo, sin embargo, los resultados les fueron menos favorables, ya que los cultivadores reforzaron su situación negociadora, al desarrollar una iniciativa en la gestión de aquella agricultura intensiva que, a menudo, impidió a los propietarios disponer libremente de sus tierras. Era imposible mejorar la producción e incrementar el valor de la tierra y, al

79 El caso del marqués de Jura Real resulta muy significativo: mientras que la persona que ocupó el título a principios del siglo XIX se había mostrado muy atenta al fomento del progreso agrario, su sucesor de finales de la centuria, residente en Madrid, limitó casi exclusivamente sus preocupaciones al cobro de la renta. Mezquita (2005), pp. 60-61. Dice este autor, citando fuentes orales, que esa evolución no fue excepcional entre los mayores propietarios de Gandía, que acabaron vendiendo a bajo precio una parte sustancial de su patrimonio.

80 En la ciudad de Castellón, el retroceso de la explotación indirecta es un buen indicador del ritmo al que avanzó el naranjo en la huerta de la ciudad: pasó de afectar a más de la mitad de la huerta en 1870 a una cuarta parte en 1900, al 11 por 100 en 1930 y al 8 por 100 en 1940. Garrido (2004), pp. 110-113. 
mismo tiempo, evitar la consolidación de la posición de ciertos colonos. Éstos, en algún momento de la primera mitad del siglo XX, compraron, a un precio muy favorable, las tierras que llevaban en arrendamiento y, en ocasiones, los propios dueños les "regalaron" una parte del terreno que cultivaban a cambio de que dejaran libre el resto, un proceso que se aceleró en la década de $1940^{81}$.

Mucho antes, en la campaña para las elecciones a Cortes de 1901, José Canalejas dio un mitin en Gandía a favor del candidato liberal del distrito. Como su oponente, Federico Trénor, era un gran propietario que explotaba la tierra sirviéndose de arrendamientos, Canalejas trató de ganarse la simpatía de los colonos: "Estas huertas espléndidas [...] son del capitalista en el registro de la propiedad [...], pero [...] bien puede decirse que son vuestras, pues en ellas está vuestro trabajo" ${ }^{\prime 82}$. No parece que los arrendatarios de la zona cuestionaran nunca de manera generalizada la legitimidad del derecho a la propiedad que asistía a sus arrendadores. De hecho, durante el siglo XX, se decantaron de forma mayoritaria hacia el catolicismo social y la derecha política confesional. Pero es bastante probable que estuvieran de acuerdo con Canalejas. En la Francia del siglo XIX, alguien señaló — para quejarseque "un arrendatario con derecho a indemnización se convertía casi en un propietario" ${ }^{\prime 83}$. Los arrendatarios de esta zona del litoral valenciano eran y se sentían propietarios. Primero, sólo de las mejoras conseguidas gracias a su trabajo; pero en no pocos casos consiguieron traducirlas, después, en títulos en el Registro de la Propiedad.

\section{Bibliografía}

ARDIT, Manuel (1991): “¿Fou l'Horta una comarca peculiar?”, Afers, 11/12, pp. 7588.

-(1993): Els homes i la terra al País Valencià (segles XVI-XVIII), Barcelona, Curial. AXELROD, Robert (1984): The evolution of Cooperation, Nueva York, Basic Books. BERNABÉ HERRERO, Juan Antonio (1907): Discurso leído en la solemne inauguración del curso de la Universidad Literaria de Valencia, Valencia, Doménech.

BHADURI, Amit (1999): On the Border of Economic Theory and History, Oxford, Oxford University Press.

BLASCO IBÁÑEZ, Vicente (1976): La barraca, Barcelona, Círculo de Lectores.

\footnotetext{
81 Garrido-Juan (1943); Fontavella (1952).

82 Citado en Garrido (1987), p. 71.

83 Congost (2000), p. 67.
} 
BURRIEL, Facundo, y OLLER, Manuel (1929): "El problema de la tierra en Valencia", en Crónica del I Congreso Diocesano de Acción Católica de Valencia, Valencia, Tip. Moderna, pp. 109-124.

CALATAYUD, Salvador; MILLÁN, Jesús, y ROMEO, María C. (1996): “La noblesa propietària en la societat valenciana del segle XIX: el comte de Ripalda i la gestió del seu patrimoni", Recerques, 33, pp. 79-101.

-(2000): "El rentismo nobiliario en la agricultura valenciana del siglo XIX", Revista de Historia Económica, XVIII, 1, pp. 79-108.

-(2002): "Les múltiples cares de la renda: propietaris i arrendataris al País Valencià", Estudis d'Història Agrària, 15, pp. 57-86.

-(2006): "Leaseholders in Capitalist Arcadia: Bourgeois Hegemony and Peasant Opportunities in the Valencian Countryside during the Nineteenth Century", Rural History, 17, 2, pp. 1-18.

CALATAYUD, Salvador; GARRIDO, Samuel; MILLÁN, Jesús, y ROMEO, María C. (2003): “Repenser le fermage. L'agriculture irriguée dans la région de Valence au XIXe siècle", en BÉAUR, Gérard; ARNOUX, Mathieu, y VARET-VITU, Anne (eds.), Exploiter la terre. Les contrats agraires de l'Antiquité à nos jours, Rennes, Association d'Histoire des Sociétés Rurales, pp. 241-254.

CARMONA, Juan, y SIMPSON, James (2003): El laberinto de la agricultura española. Instituciones, contratos y organización entre 1850 y 1936, Zaragoza, Prensas Universitarias de Zaragoza.

CASTELLANOS, Francesc, y FERNÁNDEZ-PACHECO, Joan C. (1991): “Amos i masovers: les relacions d'arrendament a València (1870-1885)", Afers, 11/12, pp, 215-225.

CAVANILLES, Antonio José (1795): Observaciones sobre la historia natural, geografía, agricultura, población y frutos del Reyno de Valencia, Madrid, Imp. Real, 2 vols.

CONGOST, Rosa (2000): "Sagrada propiedad imperfecta. Otra visión de la revolución liberal española", Historia Agraria, 20, pp. 61-93.

FONTAVELLA, Vicente (1952): La Huerta de Gandia, Zaragoza, Madrid, Consejo Superior de Investigaciones Científicas.

FRANK, Robert H. (1992): Microeconomía y conducta, Madrid, McGraw-Hill.

GARRABOU, Ramón (1985): Un fals dilema. Modernitat o endarreriment de l'agricultura valenciana, 1850-1900, Valencia, Alfons el Magnànim.

GARRIDO, Samuel (1987): El sindicalisme catòlic a la Safor. Catolicisme social i polític en una comarca del País Valencià, Gandía, Alfons el Vell.

-(1996): Treballar en comú. El cooperativisme agrari a Espanya, Valencia, Alfons el Magnànim.

-(2004): Cànem gentil. L'evolució de les estructures agràries a la Plana de Castelló (17501930), Castellón, Ayuntamiento de Castellón.

GARRIDO-JUAN, Ricardo (1943): El arrendamiento consuetudinario valenciano, Valencia, Aeternitas. 
GIMENO SANFELIU, María Jesús (1983): “Los arrendamientos de tierras a corto plazo", UNED en la provincia de Castellón, 2, pp. 129-143.

GOERLICH PESET, José M. (1982): “Revolución liberal y arrendamientos rústicos en la práctica notarial valenciana", en Estudios dedicados a Juan Peset Aleixandre, Valencia, Universitat de València, II, pp. 197-216.

HAYAMI, Yujiro, y OTSUKA, Keijiro (1993): The Economics of Contract Choice, Oxford, Clarendon Press.

MALEFAKIS, Edward (1982): Reforma agraria y revolución campesina en la España del siglo XX, Barcelona, Ariel.

MEZQUITA, Francisco (2005): "Història d'una familia”, en MEZQUITA, Francisco; FRAMIS, Maite, y ALONSO, Jesús (eds.), El marquesat de Jura Real, Simat, La Xara.

MILLÁN, Jesús (2006): “Triunfo y límites de la propiedad en el arrendamiento valenciano", en Historia de la propiedad. Costumbre y prescripción, Madrid, Colegio de Registradores de la Propiedad, pp. 374-410.

MINISTERIO DE FOMENTO (1918): Medios que se utilizan para suministrar agua de riego a las tierras y distribución de los cultivos en la zona regable, Madrid, 2 vols.

MODESTO ALAPONT, José R. (1998): A ús i costum de bon llaurador. L'arrendament de terres a l'Horta de València (1780-1860), Catarroja, Afers.

-(2004): Crisis y transformación en la gran propiedad rentista valenciana, Tesis Doctoral inédita, Universidad de Valencia.

MONFORTE BÁGUENA, Alberto (1922): El problema agrario levantino. Historia y realidad, Valencia, Tipografía Moderna.

MORÁN, Francisco (1908): "El colonato en España", en Semana Social de España. Segundo Curso. Valencia, Zaragoza, Tip. Salas, pp. 25-91.

ORELLANA y RINCÓN, Pablo de (1886): El colonato en Valencia, Valencia, Imp. Ferrer.

OTSUKA, Keijiro; CHUMA, Hiroyuki, y HAYAMI, Yujiro (1992): “Land and Labor Contracts in Agrarian Economies: Theories and Facts", Journal of Economic Literature, XXX, pp. 1.965-2.018.

PAZOS GARCÍA, Diego (1908): La cuestión agraria de Irlanda y referencias a la de Espa$\tilde{n} a$, Madrid, J. Ratés.

PONS, Anaclet (1990): “Els contractes d'arrendament al País Valencià. Una anàlisi de protocols notarials (1785-1870)", Estudis d'Història Agrària, 8, pp. 175-199.

ROBLEDO, Ricardo (1984): La renta de la tierra en Castilla La Vieja y León (1836-1913), Madrid, Banco de España.

ROMERO GONZÁLEZ, Joan (1983): Propiedad agraria y sociedad rural en la España mediterránea, Madrid, Ministerio de Agricultura.

RUIZ TORRES, Pedro (1991): "Privilegi i desigualtat en el món rural (1780-1870)", Afers, 11/12, pp. 88-100. 
SCHAMA, Simon (2004): Auge y caída del Imperio Británico, 1776-2000, Barcelona, Crítica.

SEBASTIÀ, Enric, y PIQUERAS, José Antonio (1987): Pervivencias feudales y revolución democrática, Valencia, Alfons el Magnànim. 